\title{
A list of fish species that are potentially exposed to pesticides in edge-of-field water bodies in the European Union-a first step towards identifying vulnerable representatives for risk assessment
}

\author{
Lara Ibrahim • Thomas G. Preuss • Hans Toni Ratte • \\ Udo Hommen
}

Received: 24 October 2012 / Accepted: 4 January 2013 / Published online: 17 January 2013

(C) The Author(s) 2013. This article is published with open access at Springerlink.com

\begin{abstract}
Surrogate species are used in standard toxicity tests for the environmental risk assessment of chemicals. Test results are then extrapolated to the situation in the field, which is often associated with a large degree of uncertainty. Since a vulnerable species in the field is not only characterised by its intrinsic sensitivity to a stressor but also by its potential for exposure and its population resilience, the identification of focal species based on these three components of vulnerability is needed for a more ecologically relevant risk assessment. This study listed European fish species that are susceptible to pesticide exposure in the field and thus achieved the first step towards identifying focal species for the risk assessment of pesticides for fish in Europe. A step-wise filtering approach was applied to list freshwater fish species that are native to Europe and widespread in the European Union, which inhabit streams, ditches or ponds in agricultural landscapes and therefore, are at an elevated risk of being exposed to pesticides. Out of
\end{abstract}

Responsible editor: Markus Hecker

Electronic supplementary material. The online version of this article (doi:10.1007/s11356-013-1471-x) contains supplementary material, which is available to authorized users.

L. Ibrahim • U. Hommen

Fraunhofer Institute for Molecular Biology and Applied

Ecology (IME), Schmallenberg, Germany

L. Ibrahim $(\bowtie) \cdot$ T. G. Preuss $•$ H. T. Ratte

Institute for Environmental Research, RWTH

Aachen University, Aachen, Germany

e-mail: lara.ibrahim@bio5.rwth-aachen.de the 579 fish species occurring in European freshwater, 27 species met the filtering criteria. The resulting list was verified based on monitoring studies that were conducted in agricultural landscapes over the past 20 years. Focal fish species that can be used for a more ecologically relevant environmental risk assessment of pesticides in Europe can be identified from the produced list of species by further assessing their ecological (life history and dispersal characteristics) and intrinsic sensitivities.

Keywords Ditch $\cdot$ Pond $\cdot$ Stream $\cdot$ Plant protection products $\cdot$ Aquatic

$\begin{array}{ll}\text { Abbreviations } \\ \text { EU } & \text { European Union } \\ \text { ERA } & \text { Environmental risk assessment } \\ \text { PPP } & \text { Plant protection product } \\ \text { EFSA } & \text { European Food Safety Agency } \\ \text { FOCUS } & \text { Forum for the Co-ordination of Pesticide Fate } \\ & \text { Models and their Use } \\ \text { ICE } & \text { Interspecies correlation estimation } \\ \text { SSD } & \text { Species sensitivity distribution } \\ \text { TK-TD } & \text { Toxicokinetic-toxicodynamic }\end{array}$

\section{Introduction}

In Europe, agriculture is the most dominant land use, and it accounts for almost half of the total land area of the European Union (EU) (Stoate et al. 2009). Agricultural landscapes provide a number of important ecosystem 
services whereby food, fibre and fuel are produced; water, soil and climate are regulated; and aesthetic landscapes and wildlife habitats are provided (Zhang et al. 2007). However, agriculture may result in pollution of water bodies with animal wastes, veterinary pharmaceuticals, eroded sediments, nutrients or pesticides (Davies et al. 2009).

Based on the ecosystem services approach, the European Food Safety Agency panel on plant protection products (PPPs) and their residues (EFSA 2010) categorized fish under the non-target vertebrates group for PPPs. This group includes terrestrial and aquatic vertebrates that supply the following ecosystem services: food, genetic resources, education, inspiration and aesthetics. Within this document, it is specified that wild fish should be protected at the level of individuals as well as populations whereby lethal and sublethal effects of PPPs on fish are allowed only in "small to negligible magnitudes" (EFSA 2010).

It is not possible to study all the species that might exist in the field in order to assess the risks due to exposure to pesticides; hence, the current practice in environmental risk assessment (ERA) extrapolates results from tests performed on surrogate species to the field. This extrapolation is associated with a large degree of uncertainty. In this context, EFSA (2010) suggested the identification of vulnerable representatives of key taxa. The information on these representatives along with the appropriate and already available test endpoints and species can then be used to develop protective risk assessment schemes, resulting in updated and enhanced European Ecotoxicology Guidance Documents.

Fish are one of the key taxa in risk assessment of PPPs. Currently, assessments of short-term and long-term risks due to the exposure of fish to PPPs are based on comparing simulated exposure concentrations in aquatic systems (FOCUS 2001) to endpoints derived from laboratory tests (OECD 1984; 1992a, b; 1996; 1998; 2000; 2009a, b; 2011). For exposure assessment, the simulated concentrations adopt worst-case scenarios in streams, ditches and ponds that are adjacent to agricultural fields where pesticides are applied (FOCUS 2001). For effect assessment, toxicity data are derived for surrogate species that are recommended by toxicity test guidelines (OECD 1984; 1992a, b; 1996; 1998; 2000; 2009a, b; 2011). These tests are based on the following criteria for practicality reasons: easy to rear, widely available throughout the year, can be bred and cultivated in the laboratory under disease/parasite controlled conditions, healthy and of known parentage and/or well studied by a ring test. The majority of the recommended species, however, are alien to Europe (Danio rerio, Pimephales promelas, Oryzias latipes, Poecilia reticulata, Lepomis macrochirus and Oncorhynchus mykiss). The only European fish species recommended as a standard test species in some of these guidelines are the common carp Cyprinus carpio (OECD 1984; 1992a; 1996; 1998) and
European three-spine stickleback Gasterosteus aculeatus (OECD 1996). Assessment factors, also called safety or uncertainty factors, are then used in order to extrapolate test results to values deemed protective for the specific situation (populations of native species in the field), resulting in a large degree of uncertainty that typically cannot be quantified (Calow and Forbes 2003).

Ecological modelling represents a promising and refined extrapolation tool that is often recommended but to date is rarely used for the extrapolation of effects measured in the laboratory to the situation in the field (Munns et al. 2007; Grimm et al. 2009; EFSA 2010; Galic et al. 2010; Schmolke et al. 2010). For ecological modelling to be useful for ERA, one of the most important aspects is choosing the appropriate species to be simulated. These species do not necessarily have to be standard test species, but they should be a representative of vulnerable ones (EFSA 2010; Wogram 2010b). The principle of vulnerability, as conceptualized by van Straalen (1994), can be adopted for the identification of representative species. This concept integrates external exposure, intrinsic sensitivity and population resilience to characterise the vulnerability of a species to an insult (e.g. exposure to a chemical). While vulnerable representatives have already been identified as focal species for the pesticide risk assessment for birds and mammals (EFSA 2008), this has not yet been achieved for aquatic vertebrates.

The aim of this study was to identify European fish species that are at an elevated risk of being exposed to PPPs in edge-of-field water bodies in the EU. A tiered filtering approach was applied to list fish species that are native to Europe and widespread in the EU and whose habitats are considered as worst cases in the exposure assessment, i.e. streams, ditches and ponds adjacent to agricultural fields. The resulting list was verified using data from monitoring studies.

This study constructed the first of the three pillars of the vulnerability concept (van Straalen 1994) and thus, realized the first step towards defining representative vulnerable fish species (focal fish species) for the ERA of PPPs for fish in Europe.

\section{Materials and methods}

\section{Data sources}

The Handbook of European Freshwater Fishes (Kottelat and Freyhof 2007) served as the main reference for this study. It is by far the most updated work on European fishes and includes all freshwater species recorded in inland European waters including sporadic and diadromous ones. Nomenclature in this article strictly followed this book. Accordingly, populations of Gasterosteus aculeatus in eastern European 
freshwaters and northern European coasts were called $G$. aculeatus, while populations from western Europe and the Mediterranean basin were called Gasterosteus gymnurus. For data on distribution and habitat, we kept the two species separate; however, for results on fish assemblages, both species were combined as G. aculeatus/gymnurus since it was not always clear whether the new nomenclature was adopted or not in the reviewed literature. Also, Salmo trutta "the stream-resident form" was referred to as $S$. trutta and not $S$. fario, as is still done in many studies, because the latter name does not comply with the current nomenclature code. Rhodeus amarus and Squalius cephalus were sometimes referred to as Rhodeus sericius and Leusiscus cephalus, respectively. In this study, the former synonyms were used. Where necessary, data in this handbook on habitat and distribution were complemented from (Dussling and Berg 2001), Vilcinskas (1993) as well as the online sources Fishbase (Froese and Pauly 2011) and Ecomare (Drecomm 2011). Data on fish assemblages were obtained from research articles and project reports.

Filtering criteria to list potentially exposed species to PPPs in the EU

During the review of the handbook by Kottelat and Freyhof (2007), the following species were excluded from the list of candidate species: (1) non-native to Europe since protection goals aim for native species, (2) extinct, and (3) native to Europe but not present in any of the EU member states since the scope of this list is PPPs in the EU. All remaining species were filtered by geographic range and habitat.

Regarding geographic range, the aim was to list freshwater fish species representative for EU waters in the context of ERA, and hence, European regulation (European Commission 2009, Annex I) concerning the placing of PPPs on the market was followed, which divides the EU into three mutual recognition zones ${ }^{1}$. The mutual recognition zones are defined in a way that the member states would have comparable plant health and agricultural and environmental (including climatic) conditions. For a species to be included in the list, it had to be of wide range in at least one of the zones (cut-off value was set to absence in three member countries of a zone, for details please see online resource1, sheets 7 and 8; range maps are also available in Kottelat and Freyhof (2007); however, they were complemented from Fishbase (Froese and Pauly 2011). The geographical ranges of species were assessed on the spatial level of zones to serve two purposes: (1) to exclude highly endemic or localized species from the final list of

\footnotetext{
${ }^{1}$ List of countries in zones: zone A-North: Denmark, Estonia, Latvia, Lithuania, Finland, Sweden; zone B-Centre: Belgium, Czech Republic, Germany, Ireland, Luxembourg, Hungary, Netherlands, Austria, Poland, Romania, Slovenia, Slovakia, UK; and zone CSouth: Bulgaria, Greece, Spain, France, Italy, Cyprus, Malta, Portugal.
}

representative species (these species could also be potentially exposed and are important but are to be considered on a national or regional scale and not the EU scale) and (2) to include species that are important to ERA in at least one of the zones. If we had only included the fish species that were widespread across the entire EU, then relevant species whose ranges are limited in certain zones due to climatic or geological factors would have been excluded from the list.

In terms of habitat, only fish that live in streams, ditches or ponds were considered for inclusion in the target species list. Species occurring only sporadically in those water bodies and those restricted to living in rivers, lakes, coastal lagoons, shores, estuaries, springs, reservoirs, rapids and waterfalls were excluded from the list. Streams, ditches and ponds were used as the habitat filtration criteria since, in ERA, the simulated pesticide exposure scenarios consider these habitats as worst cases because of their high potential of being contaminated with PPPs when adjacent to agricultural land (FOCUS 2001).

\section{Species list verification}

For the verification of the presence of the identified species in target water bodies, studies on fish assemblages in streams, ditches or ponds adjacent to agricultural land were included (Copp 1992; Søndergaard et al. 2005, personal communication; Ottburg and Jong 2006; Benejam et al. 2010; Copp et al. 2008; Martens et al. 2008; Clavero et al. 2009; Ottburg and Jong 2009; Liess et al. 2010; Wogram 2010a). Data from those studies were selected either based on the dimensions of the water bodies or in cases where no measurements were available on the investigated habitat, habitat name. Only habitat names implying small water body size including streamlet, brook, pool and pond were considered. The dimensions (length $\times$ width $\times$ depth) of the considered water bodies had to meet those of FOCUS scenarios (FOCUS 2001) for streams $(100 \mathrm{~m} \times 1 \mathrm{~m} \times 0.29 \mathrm{~m})$, ditches $(100 \mathrm{~m} \times 1 \mathrm{~m} \times 0.3 \mathrm{~m})$ and ponds $(30 \mathrm{~m} \times 30 \mathrm{~m} \times 1 \mathrm{~m})$; an upper limit of about twice the FOCUS size was acceptable in order not to be overly restrictive in the selection of the water bodies to be included in the study. This step allowed verifying that the listed species actually occur in edge-of-field water bodies where PPPs may exist. The studies were distributed over all three regulatory zones (European Commission 2009) and thus, were considered sufficiently representative.

\section{Results}

Out of 579 fish species listed for European freshwaters (Kottelat and Freyhof 2007), 33 species were non-native to Europe, and 14 were listed as extinct. Of the remaining 
species, only 371 were recorded in at least one of the $27 \mathrm{EU}$ member states. Of these, 147 were either highly endemic or not widespread in any of the three EU regulatory zones. Thirty one species did not typically inhabit streams, ditches or ponds, and 166 did not meet both criteria of habitat and geographic range. Hence, 27 freshwater fish species (belonging to 12 families) that met the required criteria remained and were listed as potentially exposed to PPPs in the EU (see online resource 1 for full details on all the assessed species).

The family Cyprinidae had the strongest representation (approx. $48 \%$ ) of all potentially exposed species to PPPs in the EU, followed by Gasterosteidae (approx. $11 \%$ ) and Cobitidae (approx. $7 \%$ ). Only one member of each of the families of Anguillidae, Blenniidae, Cottidae, Esocidae, Lotidae, Nemacheilidae, Percidae, Petromyzonidae and Salmonidae was present in the list of potentially exposed species (Table 1).

Except for Lota lota, Alburnoides bipunctatus and Salaria fluviatilis, all listed potentially exposed species were reported in the reviewed literature for the considered edgeof-field water bodies (Table 2), thus verifying their potential of being exposed to PPPs. A number of native and nonnative species were also reported that did not meet the filtering criteria. The native species were Squalius laetanus and Luciobarbus graellsii, which are very restricted in terms of their range across Europe, and Abramis brama, Blicca bjoerkna, Alburnus alburnus and Cyprinus carpio, which usually live in larger water bodies like lakes and rivers but can occur sporadically in the target water bodies (Table 2; abundance or occurrence was less than $10 \%$ of the total catch or total sample points, respectively). The non-native species were Carassius auratus, Gambousia holbrooki, Lepomis gibbosus, Micropterus salmoides, Misgurnus anguillicaudatus, Oncorhynchus mykiss and Pseudorasbora parva. In addition to these species being non-native, which already disqualified them from entering the final list, they were also reported with low abundance, except for Pseudorasbora parva (Table 2; abundance or occurrence was less than $10 \%$ of the total catch or total sample points, respectively, for all the listed non-native species except the latter which was reported with abundance or occurrence between 10 and $40 \%$ ).

\section{Discussion}

This study identified 27 freshwater fish species that are native to Europe, widespread in the EU, are likely to be exposed to PPPs in edge-of-field water bodies and thus, are considered representative of potentially exposed fish species in the field. However, it should be noted that the 27 listed species only represent a selection of fish that are potentially exposed to PPPs. Other species such as non-native, endemic or localized species, as well as species that sporadically can occur in small water bodies but usually inhabit bigger ones may also be exposed. Endemic or localized species only occurring in a single or few countries are important for the national or regional registration of PPPs. However, for the purpose of this study, only species were listed that are representative at the geographical level of the EU since they are widespread in at least one of the regulatory zones.

Six of the species included in the final list (Barbus meridionalis, Cobitis taenia, Cottus gobio, Lampetra planeri, Misgurnus fossilis and Rhodeus amarus) are protected under the EU Flora and Fauna Habitats Directive (Council Directive 92/43/EEC). There are various reasons for endangerment, which can generally be summarized as habitat modification, degradation and fragmentation, predation and species competition, introduction of invasive species and diseases, fishing pressure and water pollution including exposure to PPPs (Joint Nature Conservation Committee 2007).

Three of the potentially exposed species were not reported in any of the considered studies on fish assemblages. One of these species was the burbot, $L$. lota, which represents one of the more sensitive species that has been shown to disappear with the early onset of environmental degradation (Oberdorff et al. 2001). Oberdorff et al. (2001) hypothesized that the reason for this disappearance was likely linked to agricultural practices, and this may be one of the reasons why this species was not detected in any of the agricultural areas investigated in the studies used for verification of the species list. Similarly, A. bipunctatus, which is known to be an indicator species for good water quality (Copp et al. 2010), was not reported to be present in any of the agricultural areas investigated by these studies. The third species, S. fluviatilis, was reported in streams receiving pesticide runoff (Saavedra 2002 reported this species under its former name, Blennius fluviatilis). However, the streams where this species was typically reported in were of larger dimensions than those meeting the selection criteria for our study.

For prospective ERA of chemicals, current testing procedures and extrapolation methods from the lab to the field are characterised by a large degree of uncertainty and thus, likely result in the over or under estimation of true risks (Calow and Forbes 2003; Stark et al. 2004). One critical step in updating the current Ecotoxicology Guidance Documents for a more realistic ERA is the identification of representative vulnerable species of key taxa (EFSA 2010). For birds and mammals, a tiered approach stratifying species at potential risk by indicator species (screening step), generic focal species (first tier) and realistic worst cases or focal species (higher tier) are currently used in ERA (EFSA 


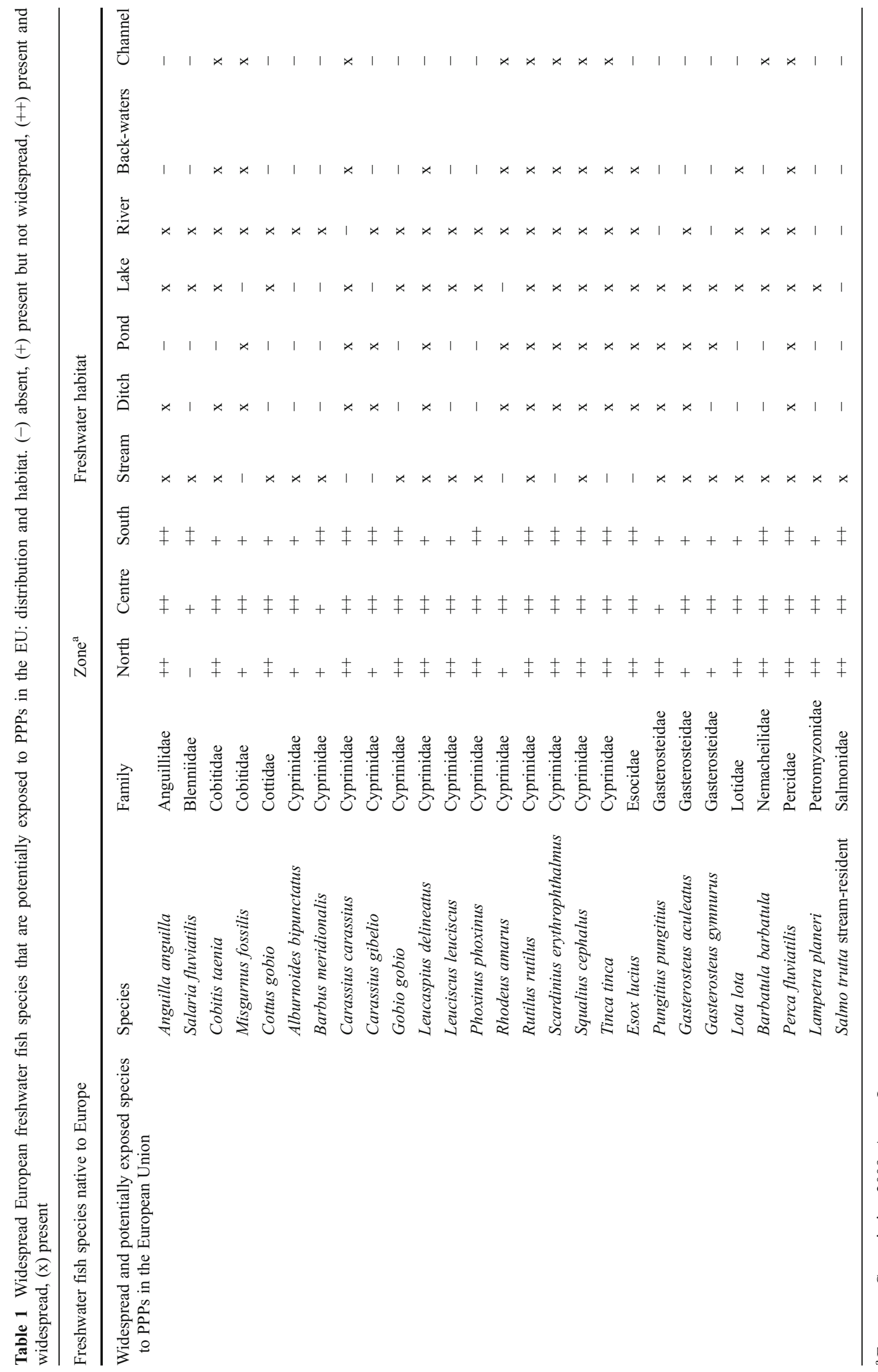

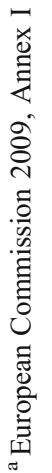




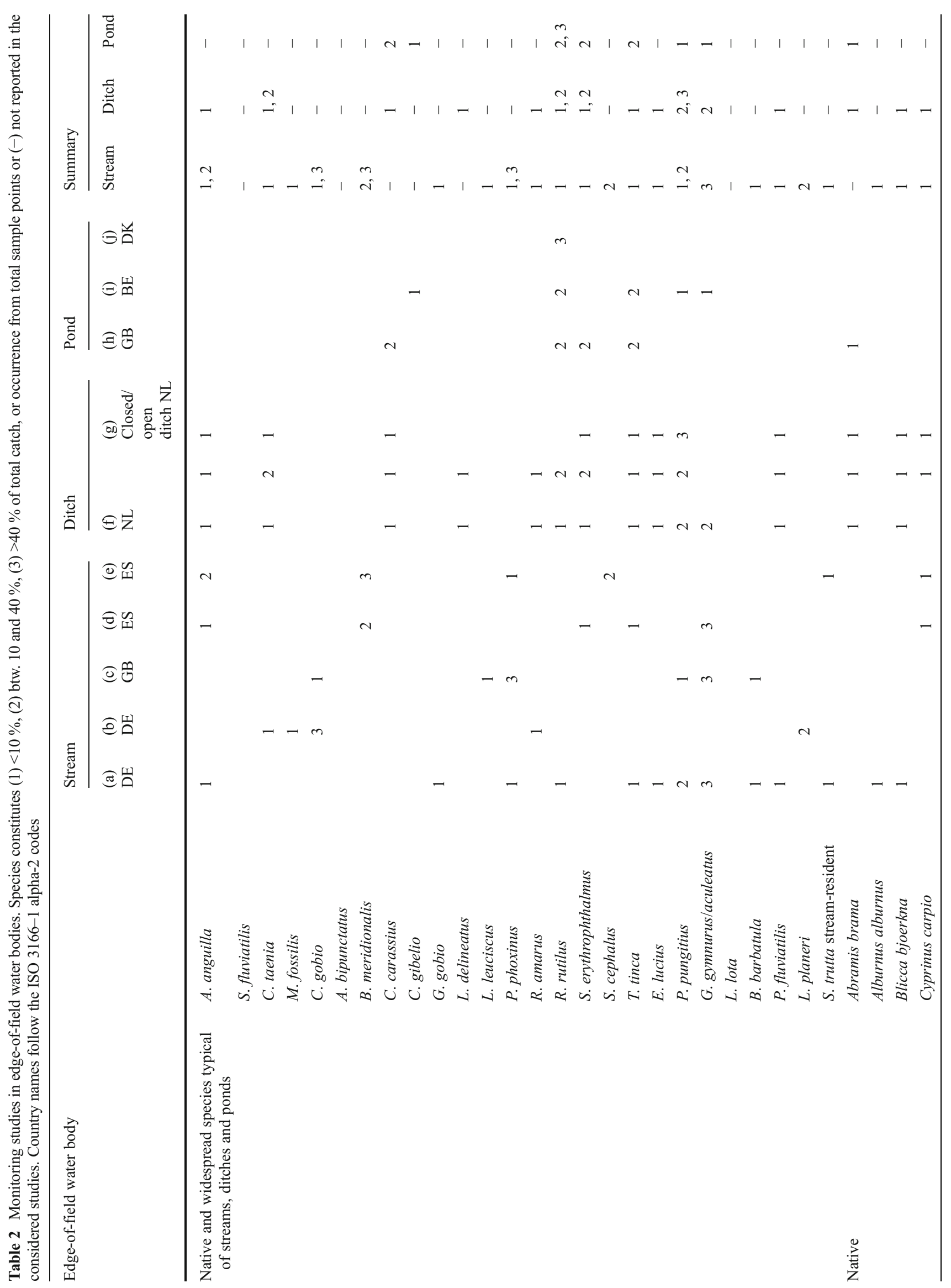




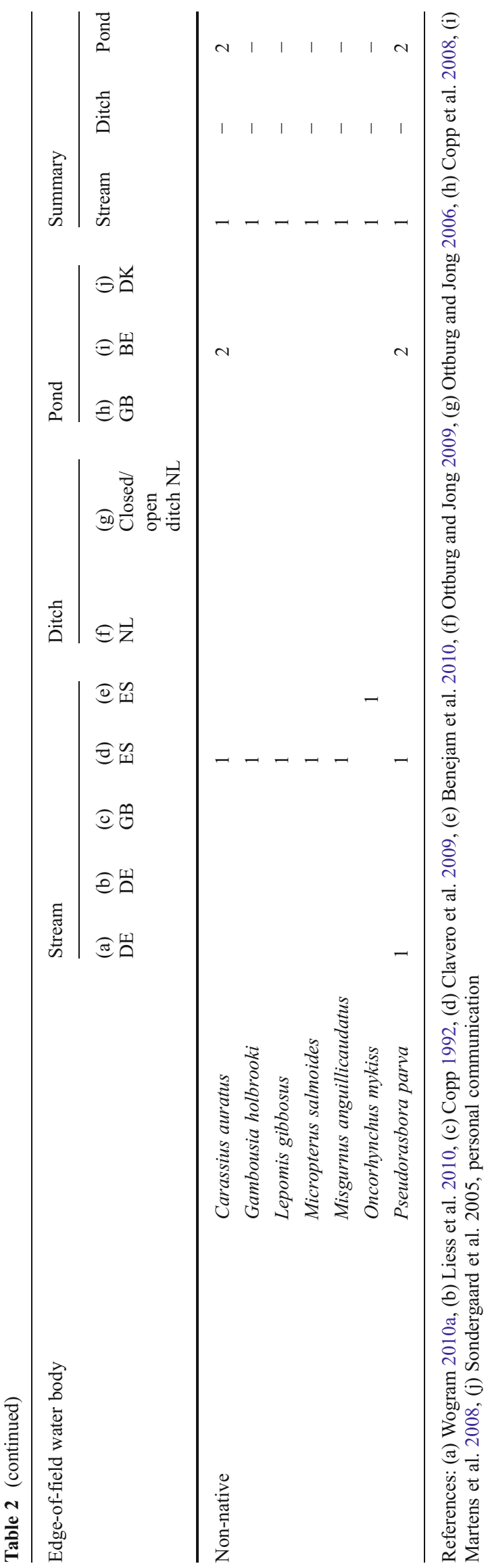

2008). Such an approach is not yet adopted for the aquatic ERA of PPPs. However, Gergs et al. (2011) recently identified realistic worst-case species for aquatic macro-invertebrates in Germany by assessing their population sustainability (reproductive traits) and recolonization potential (dispersal ability), thus linked life history traits to species vulnerability.

EFSA (2010) suggested the approaches described by De Lange et al. (2009, 2010), as well as that adopted for birds and mammals (EFSA 2008), as references for the needed identification of vulnerable representatives of key taxa in aquatic environments. Commonly, the vulnerability of a species is defined by the species' exposure to the contaminant, its intrinsic sensitivity and its population resilience. This study on fish focused on the first of the three components of vulnerability, the possibility of species to be exposed to a stressor, in this case to PPPs. The species listed here that are susceptible to pesticide exposure in the field can be used for the identification of representative vulnerable fish species for the ERA of PPPs by further assessing the species' intrinsic and ecological sensitivities.

The intrinsic sensitivity of a toxicant can only be measured in laboratory tests and is substance specific (Cairns 1986). Considering the prospective risk assessment schemes which have legally binding data requirements, it would not be reasonable to replace the established surrogate species by native species, and hence, the information gained from toxicity tests with standard laboratory species must be extrapolated to focal species in the field. The latter are to be identified ignoring toxicant specific interspecies differences in intrinsic sensitivity and focusing on the species' ecological sensitivity and potential of exposure to toxicants. For example, ERA for birds and mammals extrapolate toxicity data for rats or quails (standard test species) to voles and sky larks (focal species) by the use of assessment factors. Other approaches are also available for this extrapolation, such as species sensitivity distributions (Newman et al. 2000, Raimondo et al. 2008) and interspecies correlation estimation (Raimondo et al. 2010). It may also be possible to predict the intrinsic sensitivities of specific fish to a toxicant by combining toxicokinetic-toxicodynamic models (Ashauer and Escher 2010, Stadnicka et al. 2012) and in vitro screening techniques (Segner et al. 2003).

Ecological sensitivity or population resilience can be assessed by relating effects measured on individuals, for example, a reduction in offspring size to the population of a species while accounting for the species' life history and dispersal characteristics. Population models provide a way to compare the resilience of populations of different species (Forbes et al. 2009, 2010).

Since we were able to identify the fish species that are susceptible to exposure to PPPs in the EU and since approaches are available to investigate the intrinsic and 
ecological sensitivities of these species, the identification of representative vulnerable species (focal species) for the ERA for fish seems to be achievable within the near future.

Acknowledgments This research has been financially supported by the European Union under the 7th Framework Programme (project acronym CREAM, contract number PITN-GA-2009-238148).

We thank Profs. A. Vilcinskas and G.H. Copp, and Drs C. Sayer, C. Schaefers, G.H.P. Arts, J. Wogram and M. Gevrey for directing us to monitoring data sets and/or providing helpful input or comments on the proposed approach and the journal editor for his very helpful and relevant comments.

Open Access This article is distributed under the terms of the Creative Commons Attribution License which permits any use, distribution, and reproduction in any medium, provided the original author(s) and the source are credited.

\section{References}

Ashauer R, Escher BI (2010) Advantages of toxicokinetic and toxicodynamic modelling in aquatic ecotoxicology and risk assessment. J Environ Monit 12(11):2056-61

Benejam L, Angermeier PL, Munne A, Garcia-Berthou E (2010) Assessing effects of water abstraction on fish assemblages in Mediterranean streams. Freshwater Biol 55:628-642

Calow P, Forbes VE (2003) Does ecotoxicology inform ecological risk assessment? Environ Sci Technol 37(7):146A-151A

Clavero M, Zamora L, Pou-Rovira Q (2009) Biology and habitat use of three-spined stickleback (Gasterosteus aculeatus) in intermittent Mediterranean streams. Ecol Freshw Fish 18:550-559

Cairns J Jr (1986) The myth of the most sensitive species. BioScience 36(10):670-672

Copp GH (1992) An empirical model for predicting microhabitat of $0+$ juvenile fishes in a lowland river catchment. Oecologia 91:338-345

Copp GH, Kovac V, Siryova S (2010) Microhabitat use by streamdwelling spirlin Alburnoides bipunctatus and accompanying species: implications for conservation. Folia Zool 59(3):240-256

Copp GH, Warrington S, Wesley K (2008) Management of an ornamental pond as a conservation site for a threatened native fish species, crucian carp Carassius carassius. Hydrobiologia 597:149-155

Council Directive 92/43/EEC (1992) The conservation of natural habitats and of wild fauna and flora. Official J European Union Legislation 206(22):7

Davies BR, Biggs J, Williams PJ, Thompson S (2009) Making agricultural landscapes more sustainable for freshwater biodiversity: a case study from southern England. Aquat Conserv 19:439-447

De Lange HJ, Lahr J, Van der Pol JJC, Wessels Y, Faber JH (2009) Ecological vulnerability in wildlife: An expert judgment and multicriteria analysis tool using ecological traits to assess relative impact of pollutants. Environ Toxicol Chem 28:2233-2240

De Lange HJ, Sala S, Vighi M, Faber JH (2010) Ecological vulnerability in risk assessment - a review and perspectives. Sci Total Environ 408:3871-3879

Drecomm (2011) Ecomare. Web page. www.ecomare.nl, version (12/2011)

Dussling U, Berg R (2001) Fish in Baden-Württemberg. Ministry of agriculture and rural areas, Baden-Württemberg: Stuttgart, DE (in German)

EFSA (2008) Scientific opinion of the panel on plant protection products and their residues on a request from the EFSA PRAPeR Unit on risk assessment for birds and mammals. The EFSA Journal 734:1-181

EFSA (2010) Panel on plant protection products and their residues: scientific opinion on the development of specific protection goal options for environmental risk assessment of pesticides, in particular in relation to the revision of the guidance documents on aquatic and terrestrial ecotoxicology (SANCO/3268/2001 and SANCO/10329/2002). The EFSA Journal 8(10):1821

European Commission (2009) Regulation No 1107/2009 of the European parliament and of the council of 21 October 2009 concerning the placing of plant protection products on the market and repealing council directives 79/117/EEC and 91/414/EEC. Office for Official Publications of the European Communities, Brussels (BE)

FOCUS (2001) FOCUS surface water scenarios in the EU evaluation process under 91/414/EEC. Report of the FOCUS Working Group on surface Water Scenarios. EC Document Reference Sanco/ 4802/2001-rev.2

Forbes VE, Hommen U, Thorbek T, Heimbach F, van den Brink PJ, Wogram J, Thulke HH, Grimm V (2009) Ecological models in support of regulatory risk assessments of pesticides: developing a strategy for the future. Integr Environ Assess Manag 5:167-172

Forbes VE, Calow P, Grimm V, Hayashi T, Jager T, Palmqvist A, Pastorok R, Salvito D, Sibly R, Spromberg J, Stark J, Stillman RA (2010) Integrating population modeling into ecological risk assessment. Integr Environ Assess Manag 6:191-193

Froese R, Pauly D eds (2011) FishBase. World Wide Web electronic publication. www.fishbase.org, version (12/2011)

Galic N, Hommen U, Baveco J, van den Brink PJ (2010) Potential application of population models in the European ecological risk assessment of chemicals II: review of models and their potential to address environmental protection aims. Integrated Environ Assess Manag 6:338-360

Gergs A, Classen S, Hommen U, Preuss TG (2011) Identification of realistic worst case aquatic macroinvertebrate species for prospective risk assessment using the trait concept. Environ Sci Pollut R 18:1316-1323

Grimm V, Ashauer R, Forbes V, Hommen U, Preuss TG, Schmidt A, van den Brink PJ, Wogram J, Thorbek P (2009) CREAM: a European project on mechanistic effect models for ecological risk assessment of chemicals. Environ Sci Pollut R 16 (6):614-617

Joint Nature Conservation Committee (2007) Second Report by the UK under Article 17 on the implementation of the Habitats Directive from January 2001 to December 2006. Peterborough: JNCC. Available from: www.jncc.gov.uk/article17

Kottelat M, Freyhof J (2007) Handbook of european freshwater fishes. Cornol, Switzerand \& Berlin, Germany, Kottelat \& Freyhof

Liess M, Kattwinkel M, Kaske O, Beketov M, Steinicke H, Scholz M, Henle K (2010) Considering protected aquatic non-target species in the environmental risk assessment of plant protection products. Helmholtz Centre for Environmental Research, Leipzig, DE

Martens K, Vyverman W, Kestemont P, Losson B, De Meester L (2008) Project EV/29 - integrated management tools for water bodies in agricultural landscapes ( M A N S C A P E ). BE, Brussels

Munns WR, Gervais JA, Hoffman AA, Hommen U, Nacci DE, Nakamaru M, Sibly R, Topping CJ (2007) Modeling approaches to population-level ecological risk assessment. In: Barnthouse LW, Munns WR, Sorensen MT (eds) Population-level ecological risk assessment. Taylor and Francis, USA, pp 179-210

Newman MC, Ownby DR, Mézin LCA, Powell DC, Christensen TRL, Lerberg SB, Anderson BA (2000) Applying species-sensitivity distributions in ecological risk assessment: assumptions of distribution type and sufficient numbers of species. Environ Toxicol Chem 19:508-515

Oberdorff T, Pont D, Hugueny B, Chessel D (2001) A probabilistic model characterizing fish assemblages of French rivers: a framework for environmental assessment. Freshwater Biol 46:399-415

OECD (1984) guideline for testing of chemicals 204: fish, prolonged toxicity test, 14-day study. Adopted 4 April 1984. OECD: Paris, France 
OECD (1992a) guideline for testing of chemicals 203: fish, acute toxicity test. Adopted 17 July 1992. OECD: Paris, France

OECD (1992b) guideline for testing of chemicals 210: fish, early-life stage toxicity test. Adopted 17 July 1992. OECD: Paris, France

OECD (1996) guideline for testing of chemicals 305: proposal for updating guideline 305 , bioconcentration, flow-through fish test. Adopted 14 June 1996. OECD: Paris, France

OECD (1998) guideline for testing of chemicals 212: fish, short-term toxicity test on embryo and sac-fry stages. Adopted 21 September 1998. OECD: Paris, France

OECD (2000) guideline for testing of chemicals 215: fish, juvenile growth test. Adopted 21 January 2000. OECD: Paris, France

OECD (2009a) guideline for testing of chemicals 229: fish short term reproduction assay. Adopted 7 September 2009. OECD: Paris, France

OECD (2009b) guideline for testing of chemicals 230: 21-day fish assay, a short-term screening for oestrogenic and androgenic activity, and aromatase inhibition. Adopted 7 September 2009. OECD: Paris, France

OECD (2011) guideline for testing of chemicals 234: fish sexual development test. Adopted 28 July2011. OECD: Paris, France

Ottburg FGWA, Jong Td (2006) Fish in polder ditches; the impact of dredging on fish and amphibians in open and 'closed' ditches. Alterra: Wageningen, NL (in Dutch)

Ottburg FGWA, Jong Td (2009) Fish in polder ditches part 2; establishment and management measures in Lakerveld and Zaans Rietveld polder ditches in favor of fish. Alterra: Wageningen, NL (in Dutch)

Raimondo S, Vivian DN, Barron MG (2010) Web-based interspecies correlation estimation (Web-ICE) for Acute Toxicity: User Manual. Version 3.0. EPA/600/R-10/004. Gulf Breeze, FL

Raimondo S, Vivian DN, Delos C, Barron MG (2008) Protectiveness of species sensitivity distribution hazard concentrations for acute toxicity used in endangered species risk assessment. Environ Toxicol Chem 27:2599-2607

Saavedra DB (2002) Reintroduction of the Eurasian otter (Lutra lutra) in Muga and Fluvià basins (northeastern Spain): viability, development, monitoring and trends of the new population. $\mathrm{PhD}$ thesis, University of Girona
Schmolke A, Thorbek P, Chapman P, Grimm V (2010) Ecological models and pesticide risk assessment: current modeling practice. Environ Toxicol Chem 29:1006-1012

Segner H, Navas JN, Schaefers C, Wenzel A (2003) Potencies of estrogenic compounds in in vitro screening assays and in life cycle tests with zebrafish in vivo. Ecotox Environ Safe 54:315-322

Søndergaard M, Jeppesen E, Jensen JP (2005) Pond or lake: does it make any difference? Arch Hydrobiol 162:143-165

Stadnicka J, Schirmer K, Ashauer R (2012) Predicting concentrations of organic chemicals in fish by using toxicokinetic models. Environ Sci Technol 46(6):3273-3280

Stark JD, Banks JE, Vargas R (2004) How risky is risk assessment: the role that life history strategies play in susceptibility of species to stress. P Natl Acad Sci USA 101:732-736

Stoate C, Báldi A, Beja P, Boatman ND, Herzon I, van Doorn A, de Snoo GR, Rakosy L, Ramwell C (2009) Ecological impacts of early 21 st century agricultural change in Europe-a review. J Environ Manage 91:22-46

van Straalen NM (1994) Biodiversity of ecotoxicological responses in animals. Neth J Zool 44(1-2):112-129

Vilcinskas A (1993) Native freshwater fishes: all types: characteristics, distribution, life history. Naturbuch Verlag: Augsburg, DE (in German)

Wogram J (2010a) Ecological characterization of small streams in northern and central Germany. In: Brock TCM, Alix A, Brown CD, Capri E, Gottesbüren BFF, Heimbach F, Lythgo CM, Schulz $\mathrm{R}$, Streloke M (eds) Linking aquatic exposure and effects: risk assessment of pesticides. CRC Press, USA, pp 250-255

Wogram J (2010b) Regulatory challenges for the potential use of ecological models in risk assessments of plant protection products. In: Thorbek P, Forbes VE, Heimbach F, Hommen U, Thulke H, Van den Brink PJ, Wogram J, Grimm V (eds) Ecological models for regulatory risk assessments of pesticides: developing a strategy for the future. CRC Press, USA, pp 27-31

Zhang W, Ricketts TH, Kremen C, Carney K, Swinton SM (2007) Ecosystem services and disservices to agriculture. Ecol Econ 64:253-260 